\title{
有孔虫对南海神狐海域细粒沉积层中天然气 水合物形成及赋存特征的影响
}

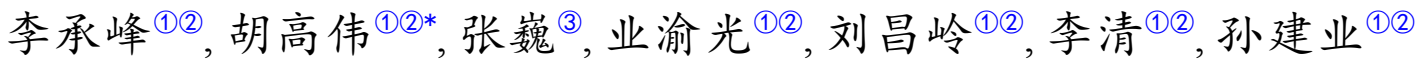 \\ (1) 国土资源部天然气水合物重点实验室, 青岛海洋地质研究所, 青岛 266071; \\ (2) 海洋国家实验室海洋矿产资源评价与探测技术功能实验室, 青岛 266071; \\ (3) 中国石油大学(华东)信息与控制工程学院, 青岛 266555 \\ *通讯作者, E-mail: hgw-623@163.com
}

收稿日期: 2016-03-11; 接受日期: 2016-05-09; 网络版发表日期: 2016-08-25

国家自然科学基金项目(批准号: 41506082, 41474119, 41376078, 41306065, 41306062)和青岛海洋科学与技术国家实验室鳌山科技创新

计划项目(编号: 2015ASKJ03)资助

\begin{abstract}
摘要海域天然气水合物多富集于渗透性较好的粗粒砂层中, 而中国南海神狐海域细粒沉积层中却发现了 高饱和度的天然气水合物, 其高丰度的有孔虫壳体是重要影响因素之一. 本文通过对南海有孔虫壳体进行分析 和水合物生成模拟实验, 从微观角度研究了有孔虫对南海水合物富集的贡献. 分别以南海纯有孔虫壳体和南海 沉积物作为介质进行水合物生长模拟实验, 通过微焦点X射线计算机断层扫描(CT)和扫描电子显微镜(SEM)观 测了典型有孔虫的孔隙结构, 并在线观测了水合物在有孔虫壳体中的生长和赋存特征. 研究结果表明, 有孔虫 壳体的存在显著提升了沉积物的有效孔隙度, 水合物优先生长于较大颗粒的有孔虫房室中, 并且主要以在有孔 虫壳体内壁附着的模式生长, 而细砂粒或泥质沉积物中则未见明显的水合物富集. 研究成果可为南海水合物成 藏机理和储层物性参数研究提供依据.
\end{abstract}

关键词神狐海域, 有孔虫, 天然气水合物, 赋存特征, X射线计算机断层扫描

\section{1 引言}

天然气水合物是一种由水分子和天然气分子(主 要为甲烷)组成的笼型水合物, 主要分布于海洋陆坡和 陆上永久冻土区. 作为未来可能的理想替代能源, 高 饱和度水合物储层是天然气水合物开发利用的重点 靶区. 受沉积物粒度制约影响, 天然气水合物多产出 于粗砂中, 在细粒沉积物中相对较少, 或饱和度相对
较低(王家生等, 2007; 苏新等, 2005). 然而, 在中国南 海神狐海域的钻探结果表明, 水合物储层砂的平均含 量仅为 $1.4 \sim 4.24 \%$, 水合物饱和度却高达 $20 \sim 40 \%$ (Wang 等, 2013), 这除了与气源供应和构造发育有关外, 还 与南海沉积物中富含丰富的有孔虫壳体有关(陈芳等, 2009, 2013). 另外, 大洋钻探(ODP)164航次在布莱克 海台地区的水合物稳定带层段中发现丰富的硅藻化 石; 韩国Ulleung盆地某钻孔水合物储层砂含量仅为

中文引用格式: 李承峰, 胡高伟, 张巍, 业渝光, 刘昌岭, 李清, 孙建业. 2016. 有孔虫对南海神狐海域细粒沉积层中天然气水合物形成及赋存特征的影响. 中国科学: 地球科学, 46: 1223-1230, doi: 10.1360/N072016-00005

英文引用格式： Li C F, Hu G W, Zhang W, Ye Y G, Liu C L, Li Q, Sun J Y. 2016. Influence of foraminifera on formation and occurrence characteristics of natural gas hydrates in fine-grained sediments from shenhu area, South China Sea. Science China Earth Sciences, doi: 10.1007/s11430-016-5005-3 
$0.5 \sim 2.2 \%$, 水合物饱和度却高达 $34.7 \sim 43.0 \%$, 与沉积物 中富含多孔微结构硅藻有关(Bahk等, 2011, 2013). 这 些古生物壳体不仅充当了沉积物的粗砂组分, 并且因 其本身所具有的多孔结构而增大了沉积孔隙空间, 从 而为天然气水合物富集提供了有利的生长环境和便 利的储集空间.

在影响水合物形成的古环境渗透特征研究中, 有 孔虫发挥着重要的指示作用(Panieri等, 2014a; 向荣等, 2010; Hill, 2004). 由于天然气水合物分解释放出的甲 烷气体在沉积物中发生厌氧氧化作用, 从而导致有孔 虫钙质壳体中的碳氧同位素存在较大变化范围, 其中 碳同位素发生负偏, 氧同位素发生正偏(李清等, 2011; Li等, 2010; Panieri等, 2014b; Hill等, 2004). 然而, 从物 性角度揭示有孔虫对水合物成藏规律影响的研究则 较少. 虽然陈芳等(2013)通过对南海神狐海域含水合 物层沉积物粒度分析和有孔虫丰度统计, 发现有孔虫 含量与水合物饱和度具有良好的对应关系, 但由于受 测试手段的制约, 人们尚不清楚微观尺度下含有孔虫 等生物组分的沉积物中水合物形成的细节过程, 从而 难以准确判断南海神狐海域水合物的赋存状态及其 储量. 如何从孔隙度、渗透性等方面探讨有孔虫对天
然气水合物在沉积物中赋存状态的影响, 从微观角度 阐释南海水合物高饱和度的原因, 是亟待解决的问题.

本文借助微焦点X射线计算机层析扫描 $(\mathrm{CT})$ 和扫 描电子显微镜(SEM) 等高分辨手段, 分别以南海神狐 海域有孔虫壳体和含有孔虫壳体的沉积物作为介质 开展了天然气水合物形成模拟实验研究, 在线观测水 合物在有孔虫内部和周围的分布特征, 探讨有孔虫对 水合物形成和富集的影响规律.

\section{2 实验部分}

\section{1 样品概况}

本实验采用的样品取自于南海神狐海域, 由广州 海洋地质调查局在HY-2006-3 航次中取样并提供. 样 品所在经纬度为 $\left(115^{\circ} 12.52363^{\prime} \mathrm{E}, 19^{\circ} 48.40299^{\prime} \mathrm{N}\right)$, 水深 为 $1554 \mathrm{~m}$, 采用重力活塞方式获取的海底浅表层沉积 物. 虽然该样品中不含天然水合物, 但样品所处位置 在 2007 年钻取水合物实物样品的站位附近(图1), 与其 地质背景基本相同, 因此该样品应具有水合物分布区 沉积物的代表性.

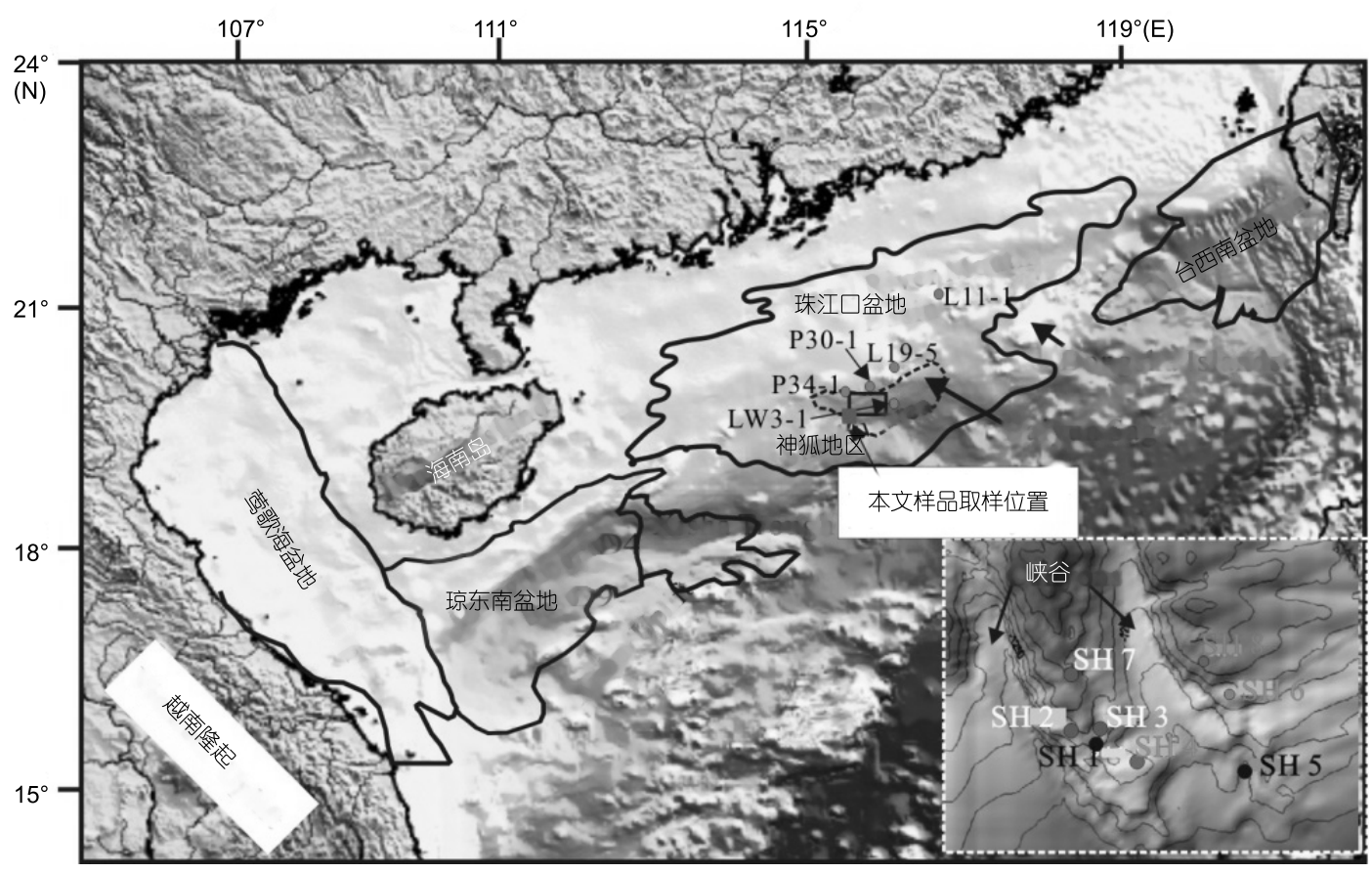

图 1 南海神狐海域取样位置图 据Wang等(2011)修改 
在实验室内取大约 $10 \mathrm{~g}$ 干燥沉积物样品, 通过溶解 篮选的方法将分散在南海沉积物中的有孔虫按照不 同粒度范围挑选出来(表1). 南海沉积物中有孔虫丰度 较高, 几乎全部为浮游型有孔虫, 粗粒 $(>150 \mu \mathrm{m})$ 居多.

\section{2 实验过程}

样品的处理和测试工作在青岛海洋地质研究所天 然气水合物重点实验室内完成, 采用日立S-3400N铇 灯丝扫描电镜对有孔虫表面形貌进行观察, 沉积物中 有孔虫内部孔隙及水合物微观分布扫描采用的是 GE 公司生产的Phoenix v|tome $\mid \mathrm{x}$ 型X射线CT. 分别选用纯 有孔虫壳体(图2a) 和含有孔虫壳体的南海沉积物 (图 $2 \mathrm{~b}$ )作为多孔介质, 在可控温高压反应釜(图2c) 内开展 甲烷水合物形成实验. 除上述沉积物介质外, 模拟实 验所采用的气体为 $99.99 \%$ 的纯甲烷气体, 接近于南海 神狐海域水合物中气体组分(Liu等, 2012); 液体采用

表 1 样品粒径及有孔虫丰度

\begin{tabular}{|c|c|c|}
\hline $\begin{array}{c}\text { 沉积物粒 } \\
\text { 径 }(\mu \mathrm{m})\end{array}$ & 重量 $(\mathrm{g})$ & 有孔虫丰度特征描述 \\
\hline$>150$ & 1.717 & $\begin{array}{c}\text { 大多为浮游有孔虫, 见极少 } \\
\text { 量管状黄铁矿 }\end{array}$ \\
\hline $63 \sim 150$ & 0.613 & $\begin{array}{c}\text { 以有孔虫幼体和碎壳居多, 少 } \\
\text { 量粗粒沉积物 }\end{array}$ \\
\hline$<63$ & 7.179 & 未见有孔虫, 全为细粒沉积物 \\
\hline
\end{tabular}
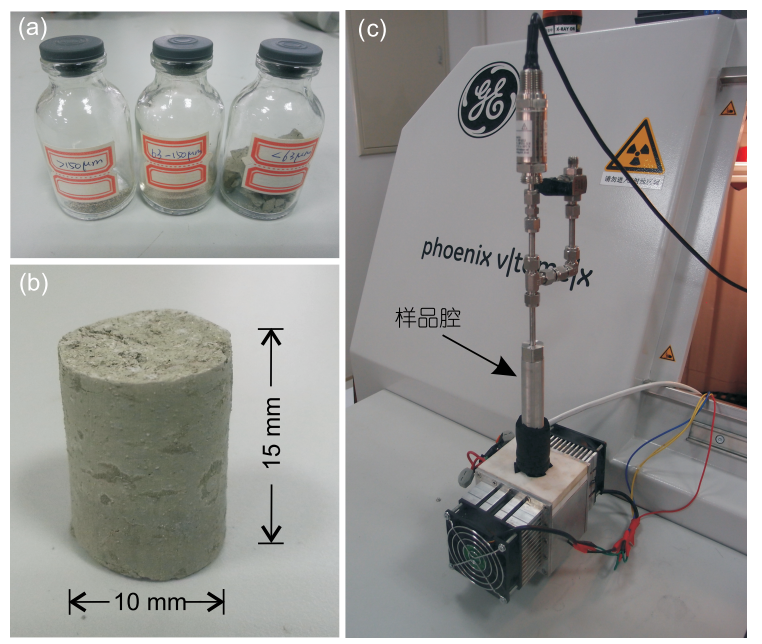

图 2 样品及实验装置

(a) 人工笁选出来的纯有孔虫壳体颗粒 (粒径 $63 \sim 150 \mu \mathrm{m}$ 和大于 $150 \mu \mathrm{m}$; (b) 含有孔虫壳体的南海沉积物; (c) 适合 $\mathrm{CT}$ 扫描的低温高压反应 釜, 用于观测水合物在沉积物和有孔虫壳体中的生长及分布变化
质量分数 $4.0 \%$ 的 $\mathrm{NaCl}$ 溶液, 近似海水浓度; 实验时温 度恒定在 $2^{\circ} \mathrm{C}$, 初始甲烷压力为 $6.5 \mathrm{MPa}$. 实验过程中分 别对原始干燥样品、经 $\mathrm{NaCl}$ 溶液润湿后的样品以及 水合物生成前后样品进行 X射线CT扫描, 观察多孔介 质中物质组成及孔隙形态的变化规律, 并利用图像灰 度分割和统计的方法反演多孔介质的孔隙度. 更加详 细的X射线 CT 图像处理与数据分析方法请参考文献 (李承峰等, 2013; 胡高伟等, 2014).

\section{3 结果与讨论}

\section{1 南海有孔虫的微观结构特征}

对从南海沉积物中挑选出来的有孔虫壳体的表 面及内部结构分别采用 SEM 和X射线CT成像技术进 行观测. 从图 $3 a$ 和 $3 b$ 中可以清楚地观察到有孔虫壳体 呈单一球形或多房室共生的结构, 且壳体表面布满了 无数大小为 $6 \sim 8 \mu \mathrm{m}$ 的微孔, 其中部分微孔被沉积物填 充, 而大多数微孔能够连通壳体内外空间(图3c).

图3d为有孔虫壳体 $\mathrm{X}$ 射线 $\mathrm{CT}$ 扫描图像(空间分辨 率 $2.0 \mu \mathrm{m})$, 从图中可以看出有孔虫壳体内部为空心, 包 含许多空的房室, 而且存在一个口孔与外部相连. 因 此, 可推断在海底沉积环境中甲烷气和水能够顺利进 入有孔虫壳体, 从而在适当的温度、压力条件下有利 于水合物的成核和生长. 此外, 该有孔虫为浮游型, 其 成岩作用微弱(陈芳等, 2013), 从而对有孔虫壳体孔隙 影响不大, 除部分有孔虫房室和壁孔被沉积物充填或 黄铁矿化外, 大部分有孔虫壳体都是有效的孔隙, 从 而为水合物的生长和富集提供了场所, 从该角度也能 够部分解释南海细粒沉积物中水合物饱和度较高的 原因.

\section{2 有孔虫对沉积物孔隙度的影响}

对图2中制备的柱状原始南海沉积物样品进行 X 射线CT扫描,经放大后的沉积物纵向剖面如图4所示, 原始沉积物样品中有孔虫大量且较为均匀地分布于 沉积物中, 除部分有孔虫壳体被泥质沉积物填充外, 大 部分壳体为空腔. 而沉积物本身粒度非常小, 在本实 验测试条件下难以观察其颗粒形貌及粒间孔隙. X射 线CT扫描原始图像经数字化重建后, 图像中的每个体 素(立方体单元, 其边长为图像分辨率, $16 \mu \mathrm{m}$ )均对应 着特定 大小的灰度值(图5). 通过统计分析区域中代 

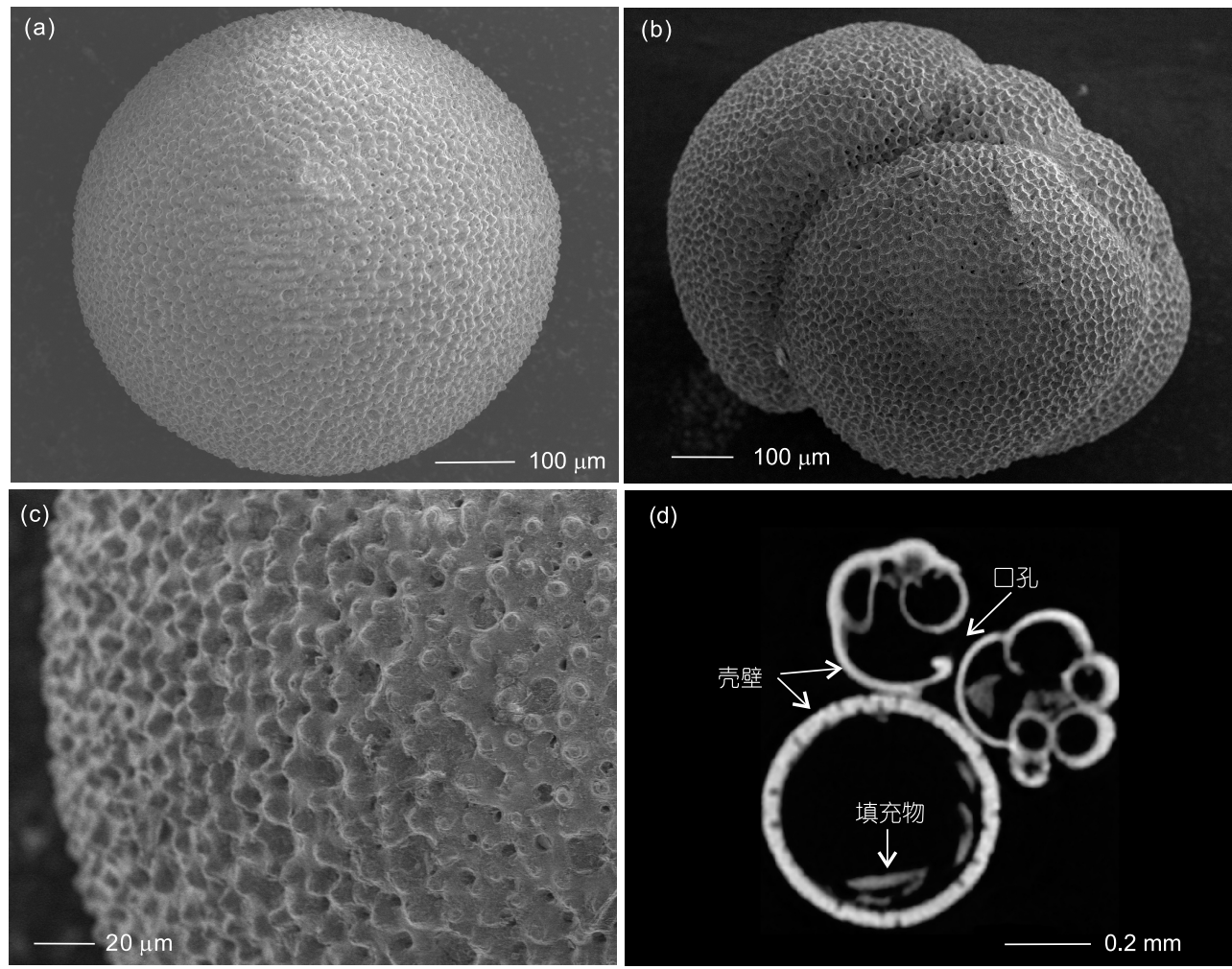

图 3 南海沉积物中典型有孔虫壳体表面和内部图像

(a) (c) 有孔虫壳体表面SEM图像; (d) 孔虫壳体内部X射线CT二维剖面图

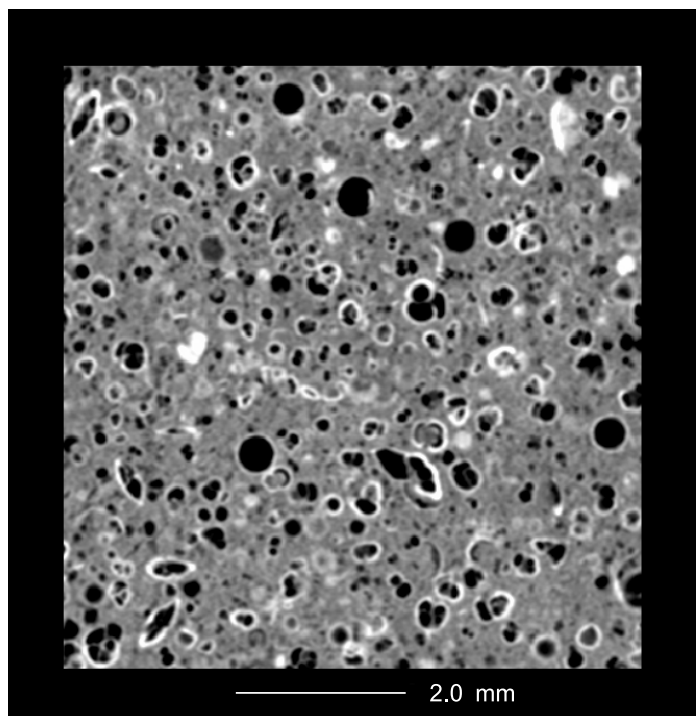

图 4 南海沉积物样品内部二维剖面

黑色部代表孔隙, 亮白色为有孔虫壳体, 其余灰色为沉积物

表有孔虫内部孔隙的灰度值范围的体素数目, 从而能 够获得有 孔虫内部有效孔隙体积占样品总体积的百

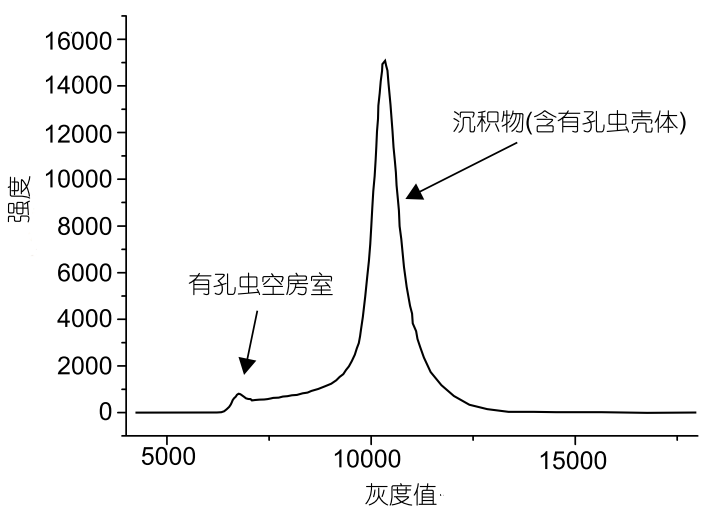

图 5 图4中样品 $X$ 射线 CT扫描灰度直方图

分比为 $18.5 \%$, 从而表明有孔虫壳体的存在能有效提 升南海沉积物的孔隙度。

3.3 水合物在有孔虫壳体内形成与分布模式讨论 通过图3中SEM和X射线 $\mathrm{CT}$ 的观测结果可知, 有 孔虫壳体连通性较好, 气体和水分 容易进入有孔虫壳 

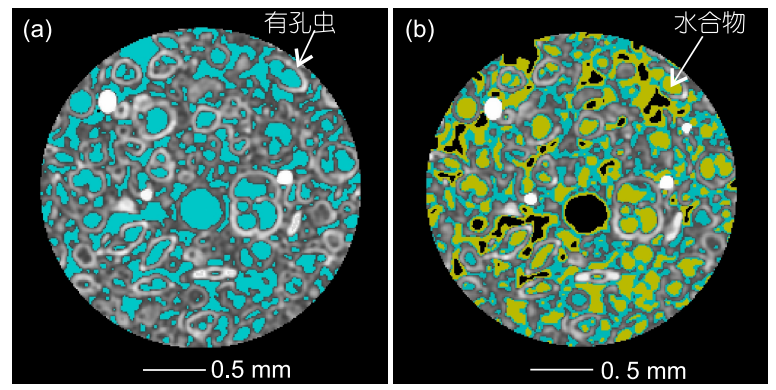

图 6 纯有孔虫壳体介质中甲烷水合物生成前(a)和生成 后 (b) 的微观分布图

黑色代表甲烷气, 蓝绿色代表 $\mathrm{NaCl}$ 溶液, 黄色代表甲烷水合物, 其 余为有孔虫壳体

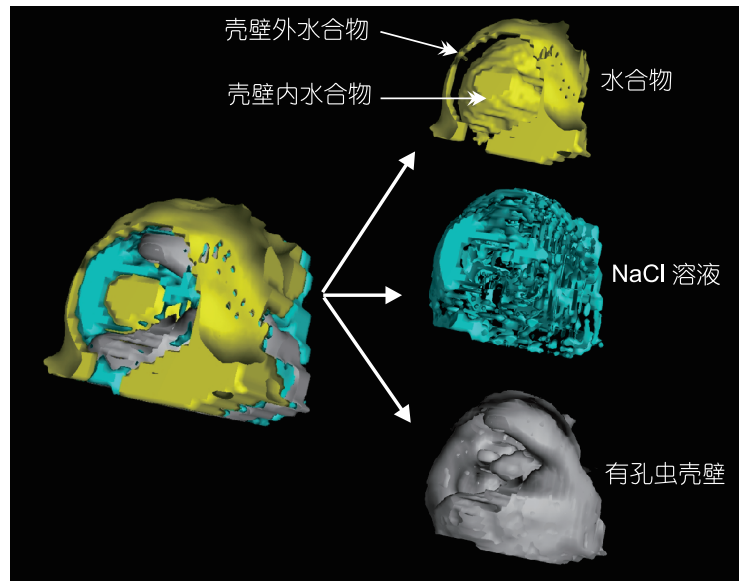

图 7 单个有孔虫壳壁内外水合物赋存状态

体内部, 为水合物的生长提供了物源条件. 有孔虫壳 体的存在增大沉积物孔隙度, 即增大了水合物的生长 空间. 通过模拟实验, 验证了有孔虫壳体内部可以形 成水合物的推测. 图6为甲烷水合物生成前后各组分 (甲烷气、水合物、水和有孔虫壳体)的空间分布对照, 从图中可以看出, 被 $\mathrm{NaCl}$ 溶液包围的有孔虫壳体内外 均有显著含量的水合物生长. 图7为单个有孔虫内外 水合物和自由水的立体分布图, 利用 $3 \mathrm{D}$ 数字重建技术 分别对水合物、水和有孔虫壳壁进行了分离, 结合有 孔虫内部的二维剖面图(图8), 从而更直观地观察到水 合物的分布特征, 证明了多孔状的有孔虫壳体是水合 物生长和富集的良好空间.

以南海沉积物作为介质模拟水合物的生长过程则 更接近于真实的海底环境, 该沉积物样品与南海神狐 海域2007年SH2钻孔中沉积物矿物组分和粒度对比如

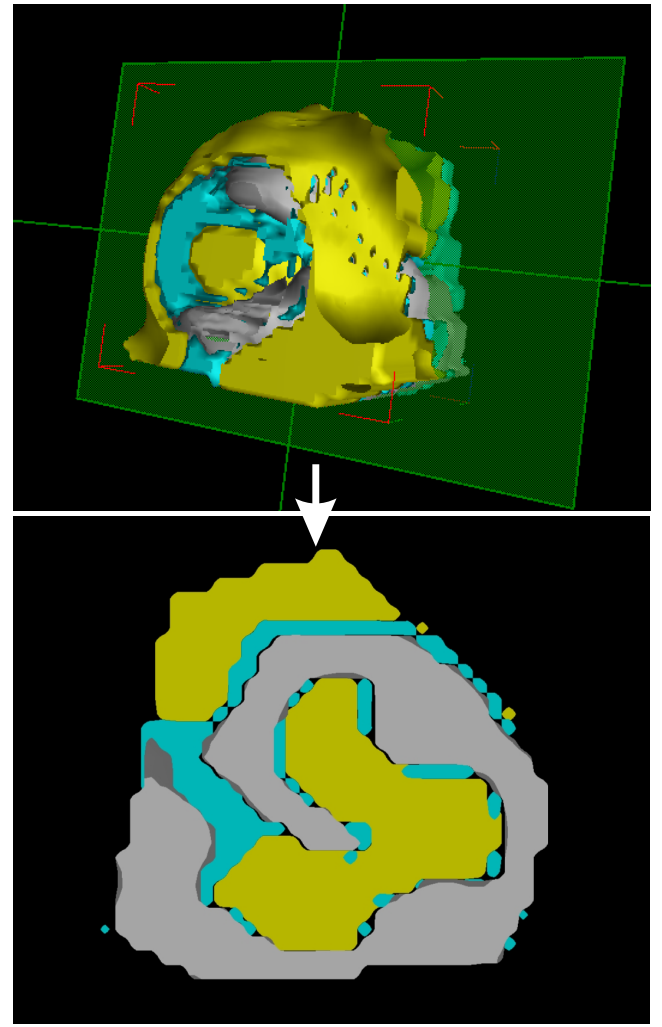

图 8 有孔虫壳体二维剖面图

黑色代表甲烷气, 蓝绿色代表 $\mathrm{NaCl}$ 溶液, 黄色代表甲烷水合物, 灰 色为有孔虫壳体

图9所示, 二者基本一致. 图10a为干燥的 南海沉积物 样品内部二维剖面图, 图10b为干燥沉积物样品经滴 入 $\mathrm{NaCl}$ 溶液润湿后的 $\mathrm{X}$ 射线CT扫描图像, 蓝色区域为 溶液所占区域, 溶液充填了大部分有孔虫的壳体, 只 有少数壳体没有渗入溶液. 如图 $10 \mathrm{c}$ 所示, 当水合物生 成后, 在有孔虫壳体内部和样品表面均有明显含量的 水合物存在. 由于南海沉积物多为粉砂和泥砂质, 其 粒间孔隙非常微小并且被黏土所填充(陈芳等, 2011), 受仪器分辨率限制, 实验过程中只能观测到有孔虫房 室(粒内孔隙)中的水合物分布, 而那些弥散在沉积物 细粒间的微小水合物晶体在 X射线 CT 图像中则难以 观察到.

为观察水合物在有孔虫壳体内部的微观赋存状 态, 对不同区域进行局部放大, 采用水合物生成前后对 比的方式, 分析有孔虫对水合物生长的控制作用. 如 图11所示, 分别选取了两个不同区域水合物生成前后 的图像进行对比. 水合物在有孔虫壳体中生长并占据 了部分气体和液体的空间, 且水合物体积较其生成之 
沉积物组分 (Wang 等, 2011) 沉积物组分 (本文样品)
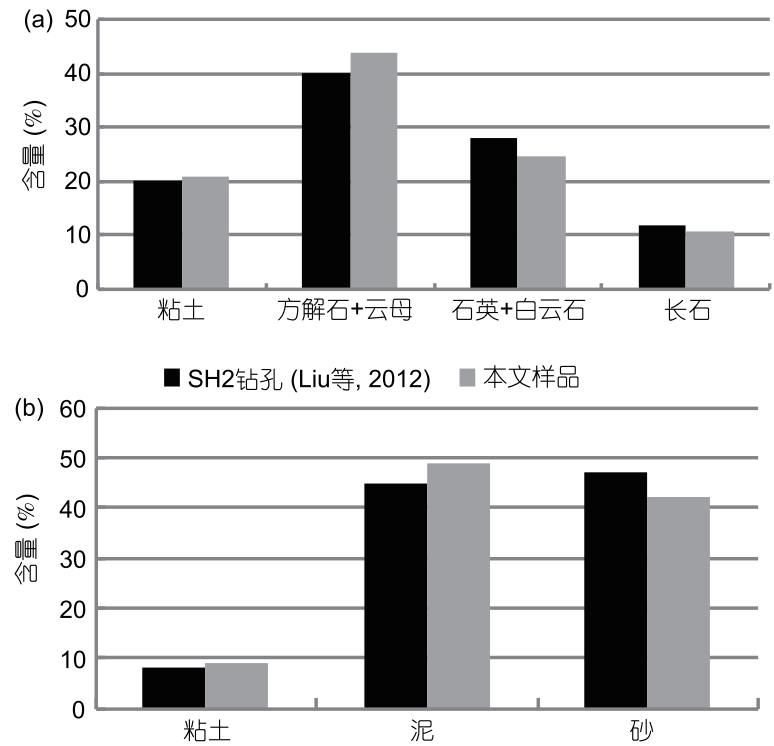

图 9 神狐海域SH2孔样品与本文样品的矿物组分对比(a) 和粒度分布对比(b)图

前的液相体积有所 增大. 由图 $11 \mathrm{a}$ 和 $11 \mathrm{~b}$ 可知, 水合物 生成前部分有孔虫壳体内部含水量较少, 随着时间的 推移水合物在其中富集, 因此可推断水合物在生长过 程中沉积物中的液体和甲烷气体通过口孔和壳壁微 孔向有孔虫壳体内部发生了迁移. 除有孔虫壳体内的 填充物外, 水合物与有孔虫壳体内壁大多直接接触, 图11b清楚地显示了水合物在有孔虫壳体内部以附着 其内壁的模式生长.

水合物在沉积物中的微观分布模式是影响水合 物地球物理勘探的重要因素. 一般认为水合物在沉积 物孔隙中有 3 种基本赋存形式: 悬浮模式(水合物与沉
积物骨架颗粒非接触)、颗粒接触模式(水合物部分粘 附在沉积物骨架颗粒表面)和胶结模式(水合物与沉积 物骨架颗粒胶结在一起, 成为骨架的一部分)(Winters 等, 2004). 存在于沉积物骨架颗粒之间的不同水合物 赋存模式对沉积物声速、电阻率、弹性模量等物理 特性参数的响应具有显著的差别(Waite等, 2009; Best 等, 2013; Ren等, 2010). 此外, 颗粒间水合物的赋存模 式随着水合物饱和度的增加也发生变化( $\mathrm{Hu}$ 等, 2010; 胡高伟等, 2014). 而沉积物中有孔虫壳体的存在不仅 增大了沉积物的“粒间空隙”, 同时又产生了“粒内孔 隙”, 在本文中即有孔虫壳体内部空房室. 一方面粒内 孔隙通过有孔虫的口孔或列孔与外部粒间孔隙相连 通, 能够为水合物的生长提供必要的物质条件; 另一 方面粒内孔隙中的水合物被有孔虫壳体所包裹, 从而 降低了水合物对沉积物颗粒的胶结作用. 因此, 我们 可以推断: 相比较颗粒间孔隙中的水合物, 颗粒内孔 隙中水合物对沉积物声速、电阻率和变形模量等参 数的响应会存在显著的差异. 诸如有孔虫壳体等粒内 孔隙中的水合物对各种沉积物物性参数的响应规律, 值得今后进行更加深入的研究.

\section{4 结论}

(1) 本文研究区沉积物样品的孔隙发育主要受有 孔虫壳体的影响, 有孔虫因其具有较高的渗透性而充 当了沉积物中的粗砂的成分. 有孔虫丰度高的区域, 沉积物的孔隙度和渗透性得到显著提升, 有利于气体 的运移和存储, 从而为水合物的成藏提供了条件.

(2) 传统的粒度和孔隙度测量方法, 主要获取的是 粒间孔隙, 而有孔虫房室内的孔隙特征难以评价, 依靠
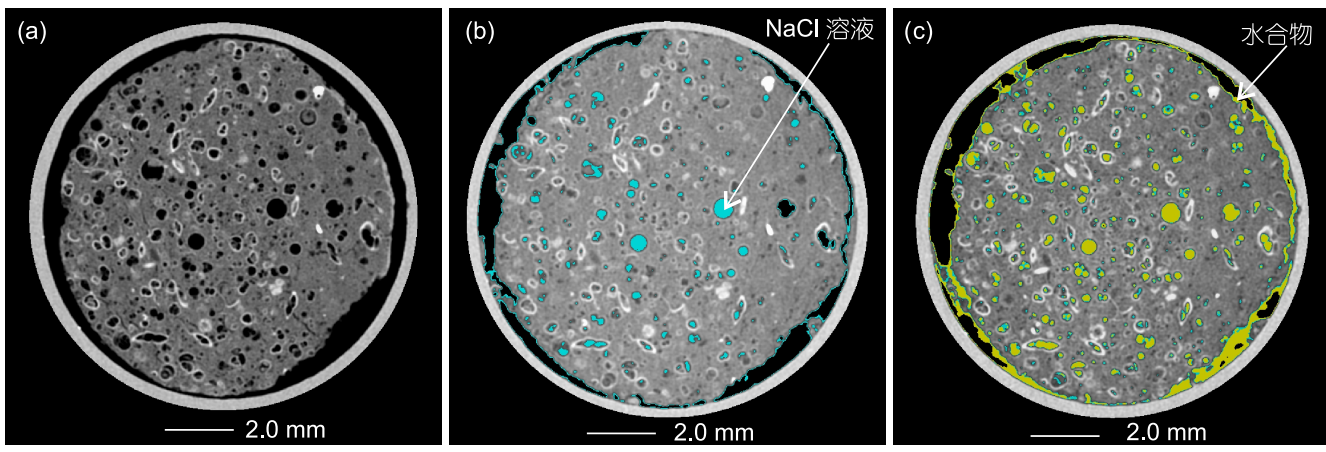

图 10 甲烷水合物在南海沉积物中生长过程微观分布

(a) 原始干燥沉积物样品; (b) 经 $4.0 \mathrm{wt} \% \mathrm{Nacl}$ 溶液润湿后的沉积物样品; (c) 水合物形成后的微观分布图 像. 黑色代表甲烷气, 黄色代表水合 物, 蓝绿色代表水, 亮白色为有孔虫壳体, 其余为沉积物 

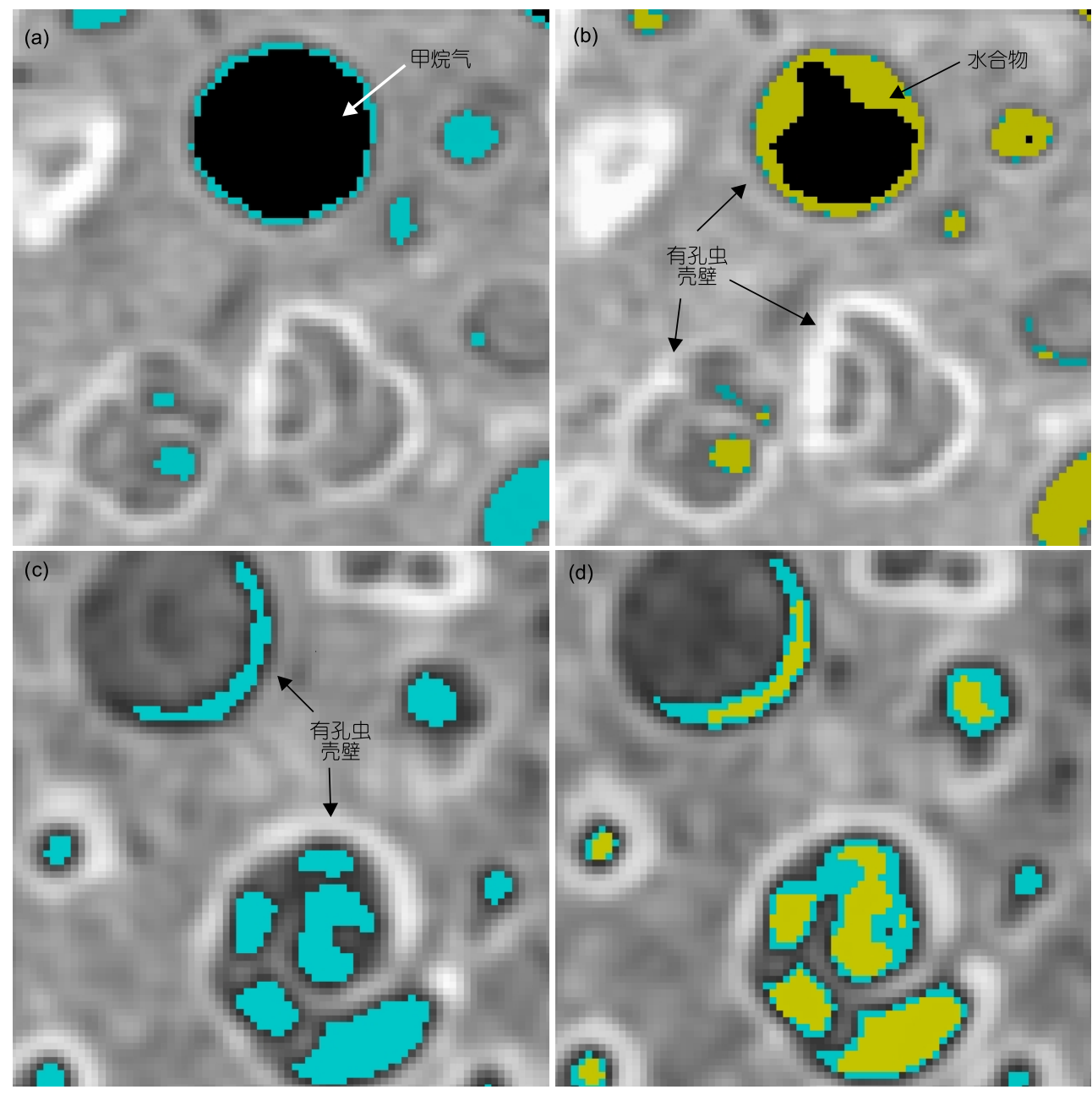

图 11 水合物生成前与生成后对比图

图(a)和图(b)为同一位置, 图(c)和图(d)为同一位置, 黑色为甲烷气体, 蓝绿色表示水, 黄色表示水合物, 亮白色为有孔虫壳体, 其余为沉积物

$\mathrm{X}$ 射线CT扫描不仅能够实现有孔虫壳体内部孔隙的 观察, 同时可在线观测水合物在有孔虫腔室内的空间 分布特征.

(3) 水合物在南海沉积物中优先在颗粒较大的有 孔虫壳体内部生长, 且主要以附着在壳体内壁的模式 生长, 这对南海水合物地震勘探和资源量估算具有重 要的参考价值.

\section{致谢感谢广州海洋地质调查局为本研究提供了地质} 样品.

\section{参考文献}

陈芳, 苏新, 周洋, 陆红锋, 刘广虎, 陈炽新, 陈超云. 2009. 南海北 部陆坡神狐海域晚中新世以来沉积物中生物组分变化及意义.
海洋地质与第四纪地质, 29: 1-8

陈芳, 周洋, 苏新, 刘广虎, 陆红锋, 王金莲. 2011. 南海神狐海域含 水合物层粒度变化及与水合物饱和度的关系. 海洋地质与第四 纪地质, 31: 95-100

陈芳, 苏新, 陆红锋, 周洋, 庄畅. 2013. 南海神狐海域有孔虫与高 饱和度水合物的储存关系. 地球科学, 38: 907-915

胡高伟, 李承峰, 业渝光, 刘昌岭, 张剑, 刀少波. 2014. 沉积物孔隙 空间天然气水合物微观分布观测. 地球物理学报, 57: 1675-1682

李承峰, 胡高伟, 业渝光, 刘昌岭, 程军, 张立凯, 郑荣儿. 2013.X 射线计算机断层扫描测定沉积物中水合物微观分布. 光电子.激 光, 23: $551-556$

李清, 王家生, 蔡峰, 陈祈, 胡高伟. 2011. 天然气水合物系统多幕 次甲烷渗漏作用的底栖有孔虫同位素响应——IODP 311航次 为例. 海洋地质前沿, 27: 29-36

苏新, 宋成兵, 方念乔. 2005. 东太平洋水合物海岭BSR以上沉积 物粒度变化与气体水合物分布. 地学前缘, 12: 234-242

王家生, 高钰涯, 李清, 杨翠萍, 陈祈, 魏清, 王晓芹, 胡高伟. 2007. 
沉积物粒度对水合物形成的制约: 来自IODP311航次证据. 地球 科学进展, 22: 659-665

向荣, 刘芳, 陈忠, 颜问, 陈木宏. 2010. 冷泉区底栖有孔虫研究进 展. 地球科学进展, 25: 193-202

Bahk J J, Um I K, Holland M. 2011. Core lithologies and their constraints on gas-hydrate occurrence in the East Sea, offshore Korea: Results from the site UBGH1-9. Mar Pet Geol, 28: 1943-1952

Bahk J J, Kim D H, Chun J H, Son B K, Kim J H, Ryu B J, Torres M E, Riedel M, Schultheiss P. 2013. Gas hydrate occurrences and their relation to host sediment properties: Results from second Ulleung Basin Gas hydrate drilling expedition, East Sea. Mar Pet Geol, 47: $21-29$

Best A I, Priest J A, Clayton C R I, Rees E V L. 2013. The effect of methane hydrate morphology and water saturation on seismic wave attenuation in sand under shallow sub-seafloor conditions. Earth Planet Sci Lett, 368: 78-87

Hill T. 2004. High-resolution records of methane hydrate dissociation: ODP Site 893, Santa Barbara Basin. Earth Planet Sci Lett, 223: 127-140

Hill T M, Kennett J P, Valentine D L. 2004b. Isotopic evidence for the incorporation of methane-derived carbon into foraminifera from modern methane seeps, Hydrate Ridge, Northeast Pacific. Geochim Cosmochim Acta, 68: 4619-4627

Hu G W, Ye Y G, Zhang J, Liu C L, Diao S B, Wang J S. 2010. Acoustic properties of gas hydrate-bearing consolidated sediments and experimental testing of elastic velocity models. J Geophys Res, 115: B02102

Li Q, Wang J, Chen J, Wei Q. 2010. Stable Carbon isotopes of benthic foraminifers from iodp expedition 311 as possible indicators of episodic methane seep events in a gas hydrate geosystem. Palaios,
25: $671-681$

Liu C, Ye Y, Meng Q, He X, Lu H, Zhang J, Liu J, Yang S. 2012. The characteristics of gas hydrates recovered from Shenhu Area in the South China Sea. Mar Geol, 307-310: 22-27

Panieri G, Aharon P, Sen Gupta B K, Camerlenghi A, Ferrer F P, Cacho I. 2014a. Late Holocene foraminifera of Blake Ridge diapir: Assemblage variation and stable-isotope record in gas-hydrate bearing sediments. Mar Geol, 353: 99-107

Panieri G, James R H, Camerlenghi A, Westbrook G K, Consolaro C, Cacho I, Cesari V, Cervera C S. 2014b. Record of methane emissions from the West Svalbard continental margin during the last $23500 \mathrm{yrs}$ revealed by $\delta^{13} \mathrm{C}$ of benthic foraminifera. Glob Planet Change, 122: $151-160$

Ren S R, Liu Y, Liu Y, Zhang W. 2010. Acoustic velocity and electrical resistance of hydrate bearing sediments. J Pet Sci Eng, 70: 52-56

Waite W F, Santamarina J C, Cortes D D, Dugan B, Espinoza , D N, Germaine J, Jiang J, Jung J W, Kneafsey T J, Shin H, Soga K, Winters W J, Yun T S. 2009. Physical properties of hydrate-bearing sediments. Rev Geophys, 47: RG4003

Wang H B, Yang S X, Wu N Y, Zhang G X, Liang J Q, Chen D F. 2013. Controlling factors for gas hydrate occurrence in Shenhu area on the northern slope of the South China Sea. Sci China Earth Sci, 56: $513-520$

Wang X J, Hutchinson D R, Wu S G, Yang S X, Guo Y Q. 2011. Elevated gas hydrate saturation within silt and silty clay sediments in the Shenhu area, South China Sea. J Geophys Res, 116: B0102

Winters W J, Pecher I A, Waite W F, Mason D H. 2004. Physical properties and rock physics models of sediment containing natural and laboratory-formed methane gas hydrate. Am Mineral, 89: 1221-1227 